\title{
Innovation in Urban Design Education
}

\author{
Mónica Sánchez-Sepúlveda ${ }^{\dagger}$ \\ GRETEL Research Group, \\ on Technology Enhanced Learning, \\ La Salle, Ramon Llull University \\ 08022 Barcelona, Spain \\ monica.sanchez@salleurl.edu \\ Isidro Navarro \\ GRETEL Research Group, \\ on Technology Enhanced Learning, \\ La Salle, Ramon Llull University \\ 08022 Barcelona, Spain \\ inavarro@salleurl.edu
}

\author{
David Fonseca \\ GRETEL Research Group, \\ on Technology Enhanced Learning, \\ La Salle, Ramon Llull University \\ 08022 Barcelona, Spain \\ fonsi@salleurl.edu \\ Jordi Franquesa \\ Barcelona School of Architecture, \\ BarcelonaTech, Polytechnic \\ University of Catalonia \\ 08028 Barcelona, Spain \\ jordi.franquesa@upc.edu \\ Marc Gené \\ Architecture Department, La Salle, \\ Ramon Llull University \\ 08022 Barcelona, Spain \\ mgene@salleurl.edu
}

\author{
Xavier Calvo \\ Architecture Department, \\ La Salle, Ramon Llull University \\ 08022 Barcelona, Spain \\ xcalvo@salleurl.edu
Ernesto Redondo
AR\&M, Barcelona School of
Architecture, BarcelonaTech,
08028 Barcelona, Spain \\ Polytechnic University of Catalonia \\ ernesto.redondo@upc.edu
}

\begin{abstract}
How can we incorporate into our educational system the emerging technologies, new processes and new habits of society to improve public motivation, implication, and satisfaction in urban decision-making processes? New technology implementations in the teaching field largely extend to all types of levels and educational frameworks. However, these innovations require approval validation and evaluation by the final users. The premise is that the technology used in Virtual Reality (VR), is familiar to the Architecture students, which preview to work on specific parameters and outcome, and on the contrary, citizens with a profile not related to the field get more excited and perceive the technology as a more efficient tool. To prove this, we use a quantitative method to evaluate the satisfaction of citizens related and not related to the Architecture field. Using an interactive visualization process in a real environment, we obtained adequate feedback that allowed the optimization of this type of experiment in future iterations. The results show that the degree of satisfaction when using an advanced visualization technology was satisfactory with a differentiation between user's profiles.
\end{abstract}

\section{CCS CONCEPTS}

Human-centered computing $\rightarrow$ Virtual reality $\bullet$ Human-centered computing $\rightarrow$ Visualization design and evaluation methods $\rightarrow$

*Article Title Footnote needs to be captured as Title Note

${ }^{\dagger}$ Author Footnote to be captured as Author Note

Permission to make digital or hard copies of part or all of this work for personal or classroom use is granted without fee provided that copies are not made or distributed for profit or commercial advantage and that copies bear this notice and the full citation on the first page. Copyrights for third-party components of this work must be honored. For all other uses, contact the owner/author(s).

TEEM'18, October, 2018, Salamanca, Spain

(C) 2018 Copyright held by the owner/author(s). XXXXX...\$15.00

https://doi.org/XXXXXX
Software and its engineering $\rightarrow$ Virtual worlds training simulations

\section{KEYWORDS}

Urbanism, Formal and informal learning, Virtual reality, Mixed method assessment, Educational innovation

\section{ACM Reference format:}

M. Sanchez et al. 2018. Innovation in Urban Design Education. In Proceedings of $6^{\text {th }}$ International Conference on Technological Ecosystems for Enhancing Multiculturality, TEEM 2018, Salamanca, Spain, October 24-26, 2018, 7 pages. https://doi.org/.

\section{INTRODUCTION}

Cities are at the forefront of global socio-economical change, making the discipline of Urbanism an important part of the sustainable development and having immediate effect on the challenges that society is facing. The physical, social and cultural changes that we are experimenting force the contemporary urbanist to a practice open to the processes of socially responsible participation and the conscious interaction of the culture that lives in each place. Is about constructing a scenario for urban evolution, imagining the conditions of transformation and proposing a process capable of incorporating new experiences into the human-environment relationship.

Present and future changes that are leading to the necessity of a faster utilization of a digital transformation strategy, can be brought by several causes like users' behavior and expectations, new economic realities, societal changes and emerging digital technologies [9]. For this, the integration of emerging technologies in the urban processes has the capability to renovate a sector's activities and models, to force the changes and 
opportunities of a mix of digital technologies and their accelerating impact across society in a strategic and prioritized way, with present and future changes in mind.

Psychosocial and post-occupational studies, new communication media and ways of collecting data and technology that can detect social, economic and environmental patterns of the urban spaces, is supporting the discipline and bringing another dimension to the practice. The discussion about the increasing integration of digital technologies and in urban spaces involves a number of questions relating to the complex processes of transformation that impact cities, like economic, social, political, and environmental. Sectors, like the University, that are involved in tackling societal challenges such as urban deterioration and unpractical city spaces, take advantage of one or more of the existing and emerging technologies.

The diffusion of Information and Communication Technologies (ICTs) is having a profound effect upon the mode through which social movements and the diverse forms of active citizenship operate from below as agents of innovation, inclusion and social development [1]. Therefore, this article describes the role and use of ICTs in the design of urban spaces in the city of Barcelona through the participation two different profiles, one group are the Architecture students and the second group are citizen that will be the final-users. Starting from the classroom, combining model with real-scale proposals using Virtual Reality (VR) in open spaces makes it possible to define a new spaceparticipation model, guided, on the local scale, by single citizens, and by a local community.

In the urban context, these initiatives could facilitate public decisions through the social re-evaluation of spaces, real and virtual, in order to respond to unsatisfied needs. Using the implemented method, students and future urbanist should be able to incorporate informal data obtained from citizens in order to improve their capabilities and digital skills in the representation of information. Consequently, designs can be executed with a suitable design, adapted to space and combining the functionality, needs, and interests of citizens.

In this article the section 2, analyzes the framework related to the education in Urbanism in the Architecture Schools. Includes the explanation of training, students, and citizenship through formal vs informal education. Section 3, explain how new challenges, like ICTs (AR/VR), results in more motivation and better skills. Section 4, exemplified the use of digital transformation in Urbanism through new ways of Urbanism. Section 5, presents and discusses examples and data, leading to the conclusions and future work of the study, which are discussed in section 6 .

\section{URBANISM: FORMAL VS INFORMAL EDUCATION}

Usually, most educational systems are designed in a regulated manner, i.e. within an educational environment and a formal student training [10]. However, in recent decades, there have been studies and research that emphasize the importance of other forms of education away from schools, regardless of the level [2, 13, 15]. Learning processes are not only confined to regulated areas but also non-formal or informal ways are present throughout a person's lifetime. To do so initially we must clearly differentiate between all types of education currently defined (Coombs, Prosser, \& Ahmed, 1973):

- Formal education: Learning typically provided by an education or a training institution, structured and leading to certification.

- Non-formal: Any organized educational activity outside the established formal system.

- Informal: Learning resulting from daily life activities related to work, family or leisure.

In the base of these definitions, the architectural education allows incorporating, in a complementary way, non-formal educational elements, such as specialized courses, as well as informal education. Formally, in Architecture Schools, the Urbanism course has traditionally relied on Project-Based Learning (PBL). Under the guidance of a tutor, students are required to develop a proposal, usually in a given location, in a process that mimics the workflow of an architectural studio. Throughout this process, students learn to integrate oftenconflicting aesthetic, constructive, structural, environmental, and usability requirements into a cohesive design [25]. Adding to this training, architects and urban designers learn about their discipline in a continuous and informal way, because the subject of their craft surrounds them almost anywhere and anytime.

Informal data related to a public space that analyze semantic, temporal and spatial patterns, aspects generally overlooked in traditional approaches, improve the education of future urban designers in order to relate the projects to the main needs of the citizenship [25]. Through Digital Transformation, students and future urbanists should be able to incorporate informal data obtained from the space, its functionality and the needs and the interests of citizens, to develop more sustainable projects and products adapted to more users and/or users with different profiles or disabilities. The need to incorporate an informal approach to the education of areas whose projects are to be used by the public is essential. The views of users are not only basic but provide information that the student should be able to assimilate into their education to improve the acquisition of skills and competencies described in their academic plans.

The informal feedback in the training of the urbanist is undoubtedly one of the determining factors of the project. In the case of the urbanist, an intangible formation should allow improving his future projects. Therefore, gamification, based mainly on behavioral theories, focuses on enhancing observation (response to stimuli), feedback cycles (knowing where I am and what little remains are missing), and reinforcement for rewards (learning appears by the stimulus).

\section{TOOLS FOR MORE MOTIVATION AND BETTER SKILLS}

Information and communications technologies (ICTs) have transformed our society and, consequently, education [7]. Currently, the ways we communicate have been changing and adapting to new devices and applications that mostly involve characteristics such as mobility, interaction and interconnection. Other studies [4] describe the opportunities offered by these emerging technologies as "creating a new kind of reality, one in 
which physical and digital environments, media and interactions are woven together throughout our daily lives." However, in different areas of knowledge, education has failed to adapt to these changes.

It is easy to find examples were the traditional class or lecture class are presented as the predominant system. This can be magnified because the student is now born into a "digital age". New university students can be defined as Digital Natives [17] or Digital Residents [27], because they coexist and use all kinds of network technologies, multiple applications and all kinds of mobile devices at very early ages. This generation is capable of adapting and quickly using all types of devices and applications for their own purposes [3].

The use of ICTs in educational methods is defined in the curricula of many undergraduate and master's degrees, including the architecture degree $[20,22,23]$. The adaptation of contents and their applications to ubiquitous learning in the fields of architecture, construction and urban design, all focusing on the student and their levels of motivation and satisfaction, has been studied recently [21]. From an academic viewpoint, these systems are used to improve the acquisition of skills and spatial competencies to analyze the visual impact of any building or architectural project.

Historically, in Architecture Schools, visualization and understanding of 3D space typically accomplished via the classical view, physical models and drawings in front of 3D models and using virtual specifications. This approach is changing due to a generational change and the continuous improvement and development of technology [25]. The act of "urbanizing" a project through Digital Transformation requires a vision for what parts of the process need to transform. Whether it is in the way students are trained and professionals work and collaborate, the way processes are executed, or in the way, it relates to the users, digital technology provides a meaningful opportunity.

Urbanism courses, inside Architecture Schools, usually tend to explore different aspects of the relationship between research and design through lectures and workshops, where students must actively engage in tasks proposed by professors and receiving feedback. However, drawing plans and urban planning do not tell us about the possibilities that can ponder the citizen participation and how they applied to the construction process of the city [12]. Emerging technologies are changing the way to conceive these processes.

In face of the enormous amount of urban data that is needed to develop a proposal, the field of Urbanism is yet to incorporate many sources of information into their workflow. Nowadays the world that surrounds us is increasingly digital, especially for the younger generations using mobile devices and cloud computing services [18], and in the specific framework of the education and professional practice of Urbanism is necessary to incorporate this new paradigm and approaches.

\section{NEW WAY OF URBANISM THROUGH DIGITAL TRANSFORMATION}

Urbanism theoretical maturity reached in the twentieth century from a combination of different disciplines that merged to rethink the city. It was a time when specialists in the field started to study more about the problems of our cities adopting new methods of research and analysis, emphasizing more in the scientific phase than the artistic one. "This may be due to a natural reaction against past practice when city planning was based on the superficial city beautiful approach, which ignored the roots of the problems and attempted only window- dressing effects." - Jose Luis Sert [16]. Urbanism developed as a new science; concerned with the structure of the city, its process of growth and decay [16].

The beginning of teaching Urbanism at the universities was born along with the texts on the subject published in that period, including: Lynch's The Image of the City (1960), Mumford's The City in History (1961), Jacobs' The Death and Life of Great American Cities (1961), Cullen's Townscape (1961), and Bacon's Design of Cities (1967). However, cities keep evolving and so the discipline that deals with it. Aside from the aesthetics, the delivery systems in urban design are changing at such a fast pace that challenge the Academia to create a pedagogy to teach them [19].

Regardless of the enormous amount of urban data to incorporate, representation technologies bring ideas into reality, allowing communication between designers, clients, contractors and collaborators [14]. This is the same as for its education. Due to the potential of virtual systems, the spatial skills and abilities of students can work with peers and professors and participate in multi-tasking/multi-user collaborative and instant tracking [5]. Recent approaches in the use of these kind of methods for the visualization of real urban spaces to improve or generate dynamic experiments:

- "Blockholm" -Stockholm, 2014-, a game based on Minecraft that has invited 100,000 users, technicians and experts in urban design and citizens to participate. The objective of the game is based on designing a smart city of the future based on the real cartographic map of the city, including topography, streets, plots, rivers, lakes, etc.

• "Play the City", implemented throughout 2012 in different cities of Holland, Belgium, Turkey and South Africa and which was based on a Word of Warcraft type game.

- "SimCity" in its different versions, used as basic system in urban planning workshops, highlighting the case of Cape Town in 2013.

They are basic proposals for zoning, for general uses at the level of an entire urbanization, or for large-scale digital work. In this sense, this experience is the closest to our approach, given that we have defined challenges to be solved by users and that generate complementary information prior to the generation of the project, knowing the type of participants, their opinions modifying the scenario and it can be interpreted as the support or rejection of a proposal.

All these cases were incorporate noteworthy aspects linked to informal teaching models: citizens generate series of opinions or suggestions, which help students to see different points of view. In this case study the participants are an active element of the project, and the student, will have the ability to learn in real 
environments and projects (Project Based Learning), allowing them to obtain and improve his spatial and social skills in a very optimal way, both formally and informally. This information improves their formal knowledge, as cases were conduct outside an academic environment.

The use of mobile devices, wearables technologies such as VR, RA, collaborative work, and gamified strategies are permeating our society thanks to its ease of use and effectiveness, both in stages training, as well as in professional and social fields $[24,26]$. Using these technologies, we can work with a new way to define urban proposals rehearsing various strategies of action in an interactive way. It is possible then, to have an effective way to collaboratively evaluate public spaces thanks to the active participation of students, professionals and end users.

\section{CASE STUDY AND RESULTS}

The behavior of a user of a new system or proposal provides information crucial for the success of its final implementation. To that end, there are quantitative strategies, like usability tests, profile tests, and satisfaction surveys. In the experimentation and scientific research, if we work with many samples (a minimum of 30-50 samples), we can manage collected data quantitatively and the results can be studied and compared in order to find statistically differences [8].

The case studied in this article includes a quantitative technique, with the variable of a gamified proposal and the use of visual ICTs, aspects that bring innovation, and immediacy. One of the tests were placed in the Museum Cosmo Caixa, Barcelona, on the Research Fair in Direct (RFD). We exposed to the public to use "wearables" technologies -RV glasses-, to know how virtual reality can help us to participate in a city-planning restructuring project in our city, such as the Superilles (supersquares) in Barcelona (Figure 1). The second test was place at the Computer Tools II (CTII) classroom to Architecture students at the La Salle, Ramon Llull University.

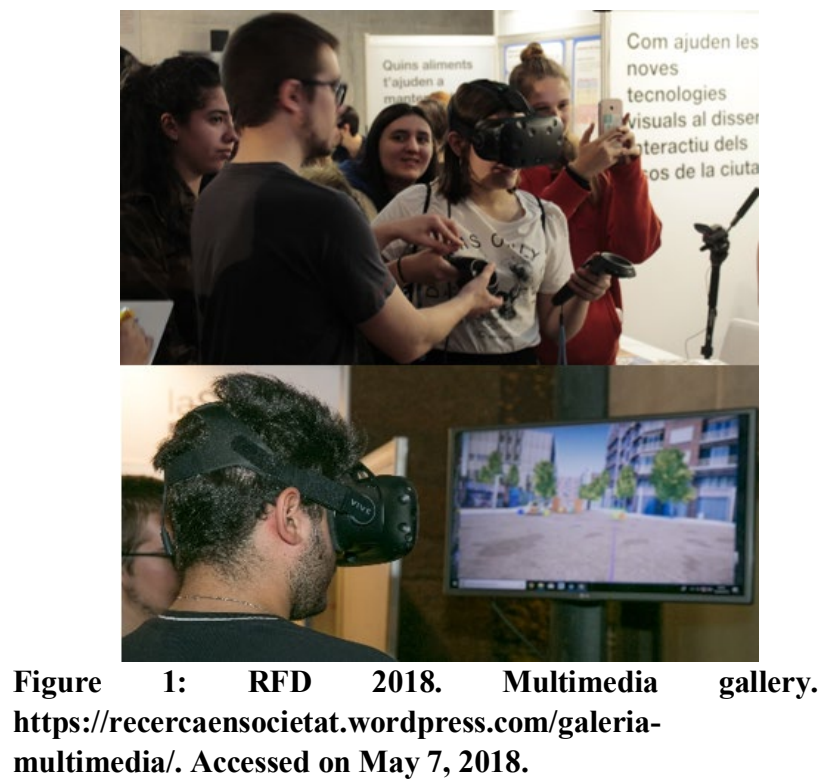

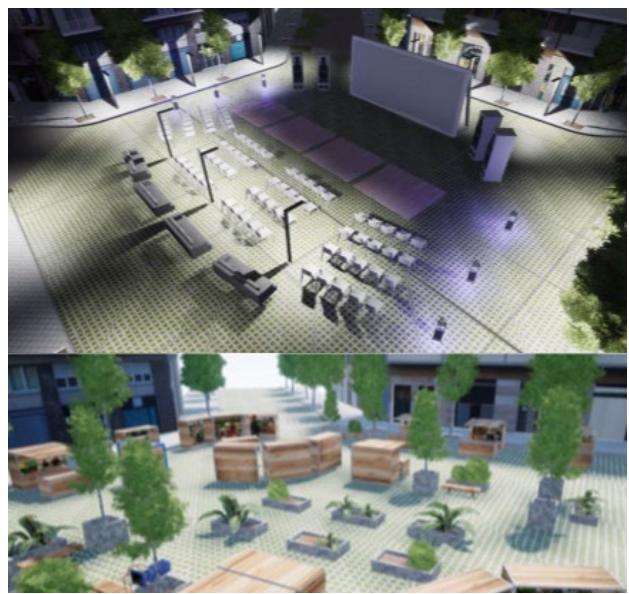

Figure 2: Example virtual reality scene.

The participants worked on urban proposals that manages to create a large public space that prioritizes the people of the neighborhood above the vehicles. With glasses of virtual reality and through interactive elements, the participants shaped the urban public space. According to their criteria and collaboratively, configuring elements such as spaces for children's games, urban gardens, vegetation, lighting, recreational and cultural activities, among others.

The virtual reality allowed participants to see in an immersive way the changes and actions that happens in the environment in real time (Figure 2), for example, in the calculation of specific lighting in a space to show a very dynamic and realistic result. Some participants' proposals, inserted into the simulated environment, have the capacity to be in constant interaction by moving and rotating actions.

For the quantitative approach, we delivered the participants questionnaires after using the virtual proposals (which is based on previous experiments done in architecture educational framework, $[6,11])$. In the first group (RFD), the citizens not related to the Architecture field we had: 46 women under 18 years old (mean age of 15.52 years with a standard deviation (SD) of 1.17), 70 men under 18 years old (mean age of 15.18 , with a SD of 1.28), 6 women over 18 years old (mean age of 25.83 , with a SD of 9.41), and 13 men over 18 years old (mean age of 23.40, with a SD of 9.09), for a total of 135 participants. In the second group, the Architecture students (CTII), we had: 15 women over 18 years old (mean age of 20.80 years with a standard deviation (SD) of 1.26), 14 men over 18 years old (mean age of 22, with a SD of 2.29), for a total of 29 students.

To both groups we design a Likert scale where participants evaluate answer from 1 to 5 their level of agreement with the statement exposed. The participants were consulted using 13 statements about different aspects: seven related to Intrinsic Motivation Inventory (IMI\#), three questions focused on the social view of the citizens (Soc-Urb\#), and the lasts three questions related architecture framework and digital skills (DigSk\#):

$\square$ IMI1: I like and have fun using virtual environments

$\square$ IMI2: I understand the space better with 3D visual systems rather than with plans and models

$\square$ IMI3: Using virtual and gamified systems requires less effort to understand 
$\square$ IMI4: The use of interactive systems generates less stress than traditional systems

$\square$ IMI5: By knowing the new visual systems, will change my way of working in the future

$\square$ IMI6: Games and interaction are useful for my future and can benefit me

$\square$ IMI7: These systems help me to interact with other users / friends / colleagues

$\square$ Soc-Urb1: These systems facilitate decision making in urban projects

$\square$ Soc-Urb2: The RA / RV systems allow the design and reevaluation of urban spaces

$\square$ Soc-Urb3: They allow to identify possible unsatisfied social needs

$\square$ Dig-Sk1: With the information obtained from the users, the students can incorporate the data to optimally modify their projects and proposals

$\square$ Dig-Sk2: The opinion of the final users helps and should serve to improve the training / competences of the student

$\square$ Dig-Sk3: These systems help to improve the digital skills in complex representation of students

Focused on the theme of the Project (based on the design and virtual interaction of new proposals for the use of urban space and the adaptation to the space of both proposals and users), the data collection made in this article is significant as identifies a series of variables to pay attention in the process of system development.

In the present study, with users outside the architectural field (RFD), the IMI average stood at 4.09, without significant differences at a global level neither by age nor by gender. This result is encouraging, since it allows us to affirm that with the adequate training and practice time students can increase their degree of motivation in the use of interactive RV systems, and therefore a better preparation for the transversal use of them. By graphically analyzing the average obtained responses related to technologies used and perceptions/motivations, we observed similar behaviors in the four groups with high motivation, but with three levels below 4, with a margin of improvement IMI4 (3.64), IMI5(3.82), IMI7(3.74) (Figure 3).

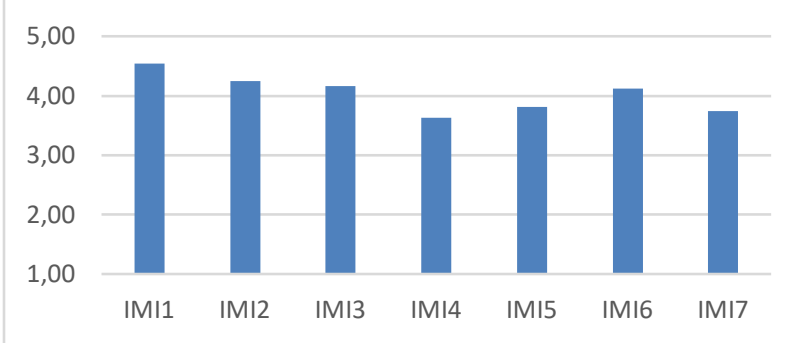

Figure 3: Intrinsic Motivation Inventory questions about the use of virtual systems in urban spaces (RFD).

Regarding the variables associated with the social/urban uses (identified with the questions marked as Soc-Urb\#), and the improvement of digital skills in the students (identified as DigSk\# questions), the overall balance is satisfactory, all indicators are equal or above 4 (Figure 4 ).

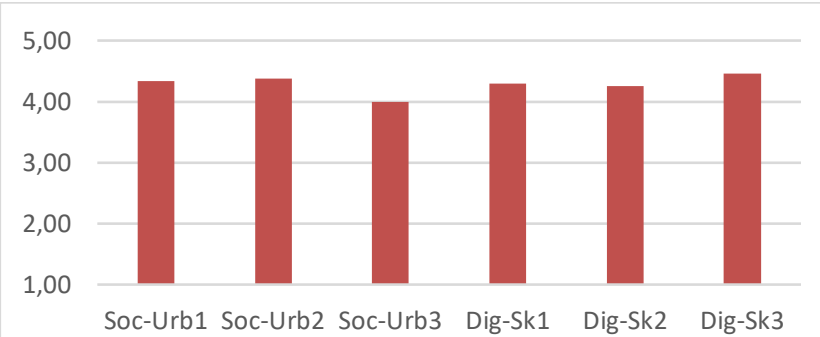

Figure 4: Usability of Virtual Systems for Social/Urban proposes and to improve Digital Skills of the students (RFD).

These results demonstrate a highly positive assessment by users regarding the issues designed. The average of the questions related to the utility of the system for the decision-making and re-planning of urban uses (Soc-Urb questions), have an average of 4.24. Higher is the result (4.34) related to the perception that these systems are an educational help to improve the digital and spatial competences of the students.

In the second group (CTII), with users inside the architectural field, the IMI average stood at 3.64 (Figure 5), without significant differences at a global level neither by age nor by gender. This lower result is related at first to the utility/complexity perceived by the system, based on the qualitative comments collected and not treated with in this article. In summary, both students and professors perceive a very powerful environment but with a long and complicated learning, without it being clear the immediate utility in the architectural and urban project process.

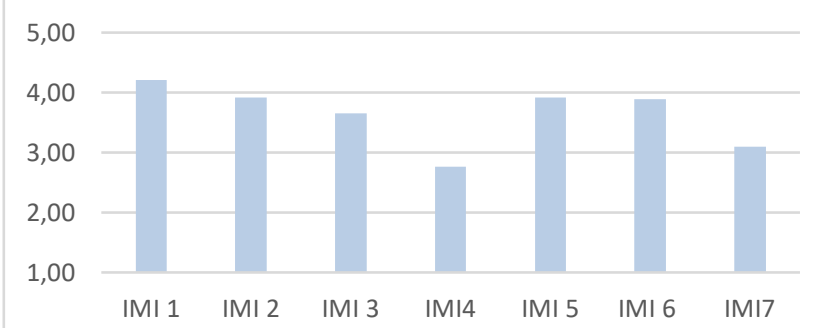

Figure 5: Intrinsic Motivation Inventory questions about the use of virtual systems in urban spaces (CTII).

Regarding the variables associated with the social/urban uses (identified with the questions marked as Soc-Urb\#), and the improvement of digital skills in the students (identified as DigSk\# questions) we have found also a lower levels in the group of CTII in front of the RFD sample. The average of the variables Soc-Urb\# for the sample of the RFD is placed in a 4.27 with respect to the 3.73 of CTII, similar levels as for the variables

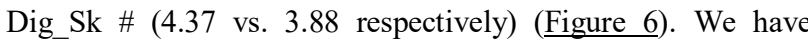
compared the responses of the two groups, RFD that are users without Architecture education, and CTII that are students and professors related with Architecture framework, Figure 7 and $\underline{8}$ ), using the Student's t-test for assessing the differences, and based on the null hypothesis (H0) of no differences in mean scores between the groups. 


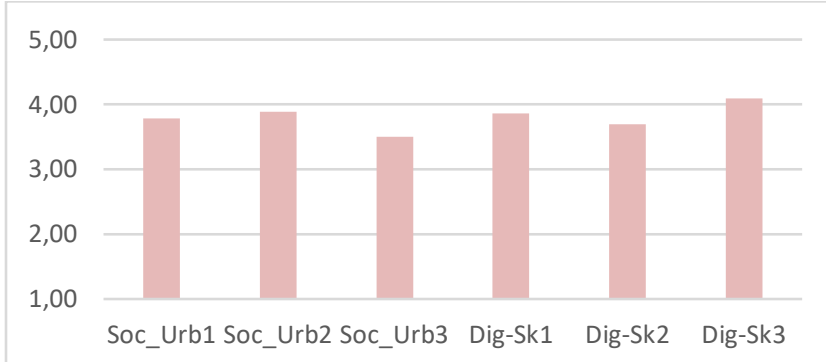

Figure 6: Usability of Virtual Systems for Social/Urban proposes and to improve Digital Skills of the students (CTII).

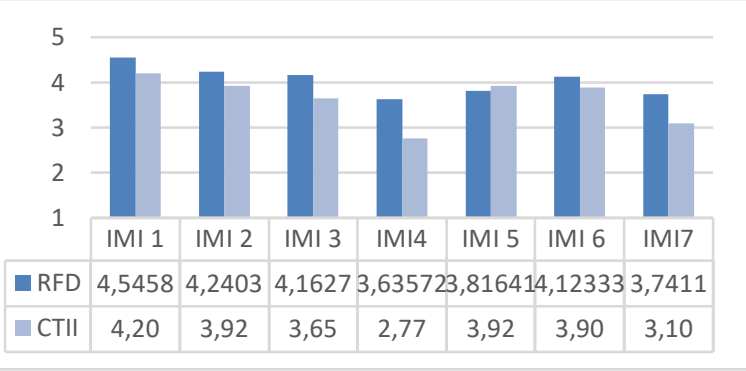

Figure 7: Comparison IMI results.

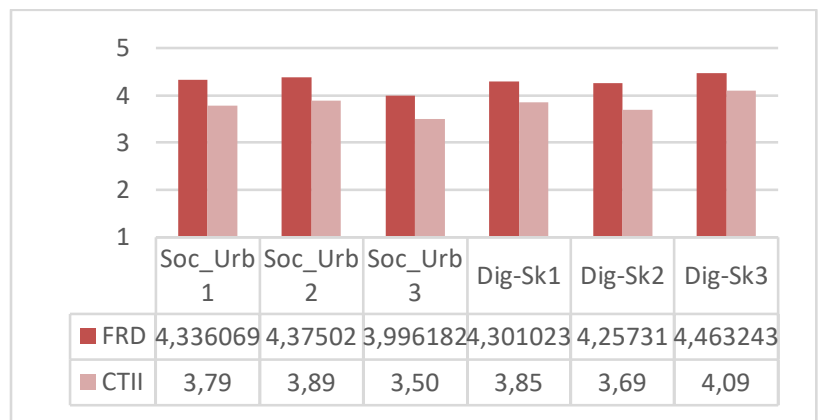

Figure 8: Comparison on Social/urban uses and improvement of digital skills using VR results.

Based on the results (Statistical significance obtained below the threshold of 0.05 , which allows to affirm a guaranteed difference of at least $95 \%$ ), we can affirm that there is a clearly differentiated behavior according to the profile of the users of the system. Regarding the variables associated with the IMI test, we have found statistically differences in the variables \# 1, \# 2, \# 4 $\& \# 7$, but in the case of variables associated with the social/urban uses (identified with the questions marked as Soc-Urb \#), and the improvement of digital skills in the students (identified as DigSk \# questions), we have found statically differences in all variables. In Table 1 we can observe the results of the comparison between samples using the t-Student (based on different variances of the samples).

\begin{tabular}{|c|c|c|}
\hline Variable & T-Statistic & $P(T<=t)$ two tailed \\
\hline IMII & 2.676780947 & 0.011235966 \\
\hline IMI2 & 1.120234757 & 0.269294989 \\
\hline$I M I 3$ & 2.041623043 & 0.048367485 \\
\hline IMI4 & 4.771683931 & 2.13037E-05 \\
\hline IMI5 & -0.634710833 & 0.528569625 \\
\hline IMI6 & 0.894901021 & 0.376193604 \\
\hline IMI7 & 1.744822319 & 0.044254121 \\
\hline SOC 1 & 2.515225107 & 0.015909398 \\
\hline$S O C 2$ & 1.866614582 & 0.034743524 \\
\hline SOC 3 & 2.387306021 & 0.021666007 \\
\hline DSK 1 & 1.87053192 & 0.034464041 \\
\hline$D S K 2$ & 3.5101366 & 0.001124552 \\
\hline DSK 3 & 1.68816103 & 0.050266944 \\
\hline
\end{tabular}

Table 1: T-Statistic and $P(T<=t$, two tailed $)$

The clearly lower averages of the users related to the architectural educational environment, can be attributed to factors such as: a lack of initial motivation in systems that have not been previously used and over which they have not been trained. Also, can be a perception of lack of utility in their needs of the professional activity to which they add the perception according to these systems are agents closest to leisure or external uses of the architectural professional field. Currently, the use of CAD (Computer Assisted Design) and BIM (Building Information Modeling) systems are the main technological tools used for modeling the architectural space, due to its fast learning curve, its high degree of implementation in subjects like workshop/projects/urban planning, and its constant use.

On the other hand, and at a user level, systems such as AR or VR are technologies that we could curiously say are closer and less specific than $\mathrm{CAD}$ or BIM. This type of interactive technologies and with a certain gamified component is found increasingly common in all types of environments, ranging from early educational phases to all kinds of applications at play, tourism, culture, etc. Undoubtedly, this aspect is what most general users perceive as part of the potential of the tools evaluated and that is demonstrated in the high result of them.

\section{CONCLUSIONS}

The main innovation of this case study is the design of a practical system to recognize the informal data generated by the citizens and by using a mixed method we can extract important data that can contribute in the education of urban design students. The results reflect that within the discipline of urbanism it is possible to introduce new technologies for the ease of the process. The use of tools such as VR is appropriate to achieve greater motivation, precision and collaboration on the part of citizens. It is also accurate that it serves as a method for students and professionals to efficiently present design proposals through the collection of informal data collection.

The use of Digital Transformation in the educational process of urban design courses, help to improve the digital skills in complex representation and allow the re-evaluation of urban spaces. In areas of formal and informal education of collaborative urban design, this method improve public motivation, implication, and satisfaction in urban decision-making processes. Participants were receptive and aware to adapt to this new 
paradigm using advanced visualization methods. This aspect not only reflects the usefulness of the method, but also the potential in the academic and competence improvement of the student, and that it is possible to define a new space-participation model, guided, on the local scale, by single citizens, and by a local community.

However, an aspect to be re-evaluated is the fact that the participants gave lower point to the affirmation that this tool allow to identify possible unsatisfied social needs and to the affirmation that the use of interactive systems generates less stress than traditional systems. For this, it would be important to improve the interaction with space and objects, the quality of the graphics and the reality of the objects. Our future experiments will be related with the study of the correlation between interaction of the user and the visualization method and the way they can manage it to serve as a tool to satisfy their needs. In addition, we will focus our future proposals to integrate of Digital Transformation in the teaching and processes of urban design and citizenship, through innovative concepts and practical methodologies.

\section{ACKNOWLEDGMENTS}

This research was supported by the National Program of Research, Development and Innovation aimed to the Society Challenges with the references BIA2016-77464-C2-1-R \& BIA2016-77464-C2-2-R, both of the National Plan for Scientific Research, Development and Technological Innovation 20132016, Government of Spain, titled "Gamificación para la enseñanza del diseño urbano y la integración en ella de la participación ciudadana (ArchGAME4CITY)", \& "Diseño Gamificado de visualización $3 D$ con sistemas de realidad virtual para el estudio de la mejora de competencias motivacionales, sociales y espaciales del usuario (EduGAME4CITY)". (AEI/FEDER, UE).

\section{REFERENCES}

[1] Di Bella, A. 2012. Digital Urbanism in Southern Italy. International Journal of E-Planning Research. 1, 4 (2012), 73-87. DOI:https://doi.org/10.4018/ijepr.2012100105.

[2] La Belle, T.J. 1982. Formal, nonformal and informal education: A holistic perspective on lifelong learning. International Review of $\begin{array}{lll}\text { Education. } 28, & 2 & \text { (1982), }\end{array}$ DOI:https://doi.org/10.1007/BF00598444.

[3] Bennett, S. et al. 2008. The "digital natives" debate: A critical review of the evidence. British Journal of Educational Technology. 39, 5 (2008), 775-786. DOI:https://doi.org/10.1111/j.1467-8535.2007.00793.x.

[4] Bower, M. et al. 2010. Blended reality: Issues and potentials in combining virtual worlds and face-to-face classes. ASCILITE 2010 - The Australasian Society for Computers in Learning in Tertiary Education. (2010), 129-140.

[5] Calongne, C.M. 2008. Educational Frontiers: Learning in a VIRTUAL WORLD. Educause Review. 43, (2008), 36-48. DOI:https://doi.org/10.1007/s00371-007-0182-z.

[6] David Fonseca, Isidro Navarro, Sergi Villagrasa, Ernest Redondo, F. V. 2017. Sistemas de Visualización Gamificados para la mejora de la Motivación Intrínseca en Estudiantes de Arquitectura. CINAIC 2017 IV Congreso Internacional sobre Aprendizaje, Innovación y Competitividad (Zaragoza, 2017), 209-214.

[7] Dede, C. 2000. Emerging influences of information technology on school curriculum. Journal of Curriculum Studies. 32, 2 (2000), 281303. DOI:https://doi.org/10.1080/002202700182763.

[8] Delamont, S. and Atkinson, P. 2010. Editorial. Qualitative Research.

[9] Digital transformation: online guide to digital business transformation: 2016. http://www.i-scoop.eu/digital-transformation/ [Retrieved on 20/12/2017].

[10] Fonseca, D. et al. 2016. Informal interactions in 3D education: Citizenship participation and assessment of virtual urban proposals.
Computers in Human Behavior. 55, (2016), 504-518. DOI:https://doi.org/10.1016/j.chb.2015.05.032.

[11] Fonseca, D et al. 2017. Student motivation assessment using and learning virtual and gamified urban environments. $A C M$ International $\begin{array}{llll}\text { Conference Proceeding } & \text { Series. }\end{array}$ DOI:https://doi.org/10.1145/3144826.3145422.

[12] García-Pablos, J.M. 2012. Perspectivas Urbanas 5: La docencia de lo urbano. Mairea Libros.

[13] Harrop, D. and Turpin, B. 2013. A Study Exploring Learners' Informal Learning Space Behaviors, Attitudes, and Preferences A Study Exploring Learners' Informal Learning. New Review of Academic Librarianship. $\quad 1, \quad 1 \quad$ (2013), $37-41$. DOI:https://doi.org/10.1080/13614533.2013.740961.

[14] Horne, Margaret and Thompson, E.M. 2008. The role of virtual reality in built environment education. Journal for Education in the Buil Environmen. 3, (2008), 5--24.

[15] Jamieson, P et al. 2005. Moving Beyond the Classroom: Accommodating the Changing pedagogy of higher education. Forum of the Australasian Association for Institutional Research (2005), 17-23.

[16] Krieger, A. and Saunders, W.S. 2009. Where and How Does Urban design Happen? Urban Design. (2009), xix, 368 p.

[17] Margaryan, A. et al. 2011. Are digital natives a myth or reality? University students' use of digital technologies. Computers \& Education. $56, \quad 2 \quad$ (2011), $\quad 429-440$. DOI:https://doi.org/10.1016/j.compedu.2010.09.004

[18] Moreira, F et al 2017. Evolution and use of mobile devices in higher education: A case study in Portuguese Higher Education Institutions between 2009/2010 and 2014/2015. Telematics and Informatics. (2017). DOI:https://doi.org/10.1016/j.tele.2016.08.010.

[19] No Title: 2018, http://commonedge.org/architectural-education-willhave-to-change-or-risk-becoming-irrelevant/. Accessed: 2018-02-05.

[20] Reffat, R. 2007. Revitalizing architectural design studio teaching using ICT: Reflections on practical implementations. International Journal of Education and Development using Information and Communication Technology (IJEDICT). 3, 1 (2007), 39-53.

[21] Sánchez Riera, A. et al. 2015. Geo-located teaching using handheld augmented reality: good practices to improve the motivation and qualifications of architecture students. Universal Access in the Information Society. 14, 3 (2015), 363-374. DOI:https://doi.org/10.1007/s10209-014-0362-3.

[22] Sariyildiz, S. and Veer, P. Der 1998. The role of ICT as a partner in Architectural Design Education. Design Studio Teaching EAAE. (1998). Tinio, V.L. 2005. ICT in Education. Essential.

[24] Valls, F. et al. 2015. E-learning and serious games: New trends in architectural and urban design education. Lecture Notes in Computer Science (including subseries Lecture Notes in Artificial Intelligence and Lecture Notes in Bioinformatics).

[25] Valls, F. et al. 2017. Urban data and urban design: A data mining approach to architecture education. Telematics and Informatics.

[26] Vicent, L. et al. 2015. Virtual learning scenarios for qualitative assessment in higher education 3D arts. Journal of Universal Computer Science. 21, 8 (2015), 1086-1105.

[27] White, D.S. and Le Cornu, A. 2011. Vistiors and residents: A new typology for online engagement. First Monday. 16, 9 (2011). DOI:https://doi.org/10.5210/fm.v16i9.3171. 